\title{
Article \\ Application Ranges of EPB Shield TBM in Weathered Granite Soil: A Laboratory Scale Study
}

\author{
Tae-Hwan Kim ${ }^{1}$, In-Mo Lee ${ }^{2}$, Hee-Young Chung ${ }^{3}{ }^{\mathbb{C}}$, Jeong-Jun Park ${ }^{4}$ and Young-Moo Ryu ${ }^{4, * \mathbb{C}}$ \\ 1 Eco Infra Solution Team 3, SK Engineering\&Construction, Seoul 03149, Korea; marineboy@sk.com \\ 2 School of Civil, Environmental and Architectural Engineering, Korea University, Seoul 02841, Korea; \\ inmolee@korea.ac.kr \\ 3 Technology Research Team, Incheon International Airport Corporation, Incheon 22382, Korea; \\ heeyoung.chung@airport.kr \\ 4 Advanced Railroad Civil Engineering Division, Korea Railroad Research Institute, Uiwang-si 16105, Korea; \\ jjpark@krri.re.kr \\ * Correspondence: ymryu@krri.re.kr
}

Citation: Kim, T.-H.; Lee, I.-M.; Chung, H.-Y.; Park, J.-J.; Ryu, Y.-M. Application Ranges of EPB Shield TBM in Weathered Granite Soil: A Laboratory Scale Study. Appl. Sci. 2021, 11, 2995. https://doi.org/ 10.3390/app11072995

Academic Editor: Fernando Marques

Received: 28 January 2021

Accepted: 24 March 2021

Published: 26 March 2021

Publisher's Note: MDPI stays neutral with regard to jurisdictional claims in published maps and institutional affiliations.

Copyright: (c) 2021 by the authors. Licensee MDPI, Basel, Switzerland. This article is an open access article distributed under the terms and conditions of the Creative Commons Attribution (CC BY) license (https:// creativecommons.org/licenses/by/ $4.0 /)$.

\begin{abstract}
Soil conditioning is a key factor in increasing tunnel face stability and extraction efficiency of excavated soil when excavating tunnels using an earth pressure balance (EPB) shield tunnel boring machine (TBM). Weathered granite soil, which is abundant in the Korean Peninsula (also in Japan, Hong Kong, and Singapore), has different characteristics than sand and clay; it also has particle-crushing characteristics. Conditioning agents were mixed with weathered granite soils of different individual particle-size gradations, and three characteristics (workability, permeability, and compressibility) were evaluated to find an optimal conditioning method. The lower and upper bounds of the water content that are needed for a well-functioning EPB shield TBM were also proposed. Through a trial-and-error experimental analysis, it was confirmed that soil conditioning using foam only was possible when the water content was controlled within the allowable range, that is, between the upper and lower bounds; when water content exceeded the upper bound, soil conditioning with solidification agents was needed along with foam. By taking advantage of the particle-crushing characteristics of the weathered granite soil, it was feasible to adopt the EPB shield TBM even when the soil was extremely coarse and cohesionless by conditioning with polymer slurries along with foam. Finally, the application ranges of EPB shield TBM in weathered granite soil were proposed; the newly proposed ranges are wider and expanded to coarser zones compared with those proposed so far.
\end{abstract}

Keywords: soil conditioning; earth pressure balance shield; weathered granite soil; foam; polymer; excavation

\section{Introduction}

Tunneling work utilizing earth pressure-balanced (EPB) shield tunnel boring machines (TBM) achieve face stability by filling the working chamber with the excavated soil and applying chamber pressure (face support pressure) toward the tunnel face. Soil conditioning is needed to increase the tunnel face stability and extraction efficiency of excavated soils through screw conveyers. Soil conditioners such as foams and polymers are mostly injected into the front of the cutter-head during TBM excavation. They are sometimes injected into the excavation chamber and the screw conveyor as well when necessary. The appropriate mixing ratio of the soil conditioning agents added to the excavated soil can be derived through trial and error by evaluating three characteristics of the conditioned soils, namely workability, compressibility, and permeability. The workability was found to be reasonable when the slump value of the conditioned soil was between $10 \mathrm{~cm}$ and $20 \mathrm{~cm}$ [1-5]. Furthermore, Wilms [6] suggested that a conditioned soil permeability coefficient less than $1 \times 10^{-3} \mathrm{~cm} / \mathrm{s}$ was required to prevent groundwater inflow into the working 
chamber from the tunnel face when tunneling below the groundwater level. Budach [3] proposed a compressibility value of $1.9 \% / 0.5$ bar or above for conditioned soil so that the face support pressure will be applied uniformly to the tunnel face in the working chamber and excavated materials will be efficiently extracted from the chamber through screw conveyors. In addition, many other studies were conducted recently, either to find optimal soil conditioning parameters or to assess the effectiveness of soil conditioning and/or EPB TBM performance [7-9].

Budach and Thewes [1] proposed choosing appropriate soil conditioning agents based on the particle-size gradation curves in the coarse ground shown in Figure 1; however, we would like to emphasize that the appropriate mixing ratio of the soil conditioning agents might also depend on the characteristics of the soil itself. The characteristics of weathered granite soil with rock origin of granite or granitic gneiss are different from those of sand and clay. The generally understood characteristics of this soil are as follows [10].

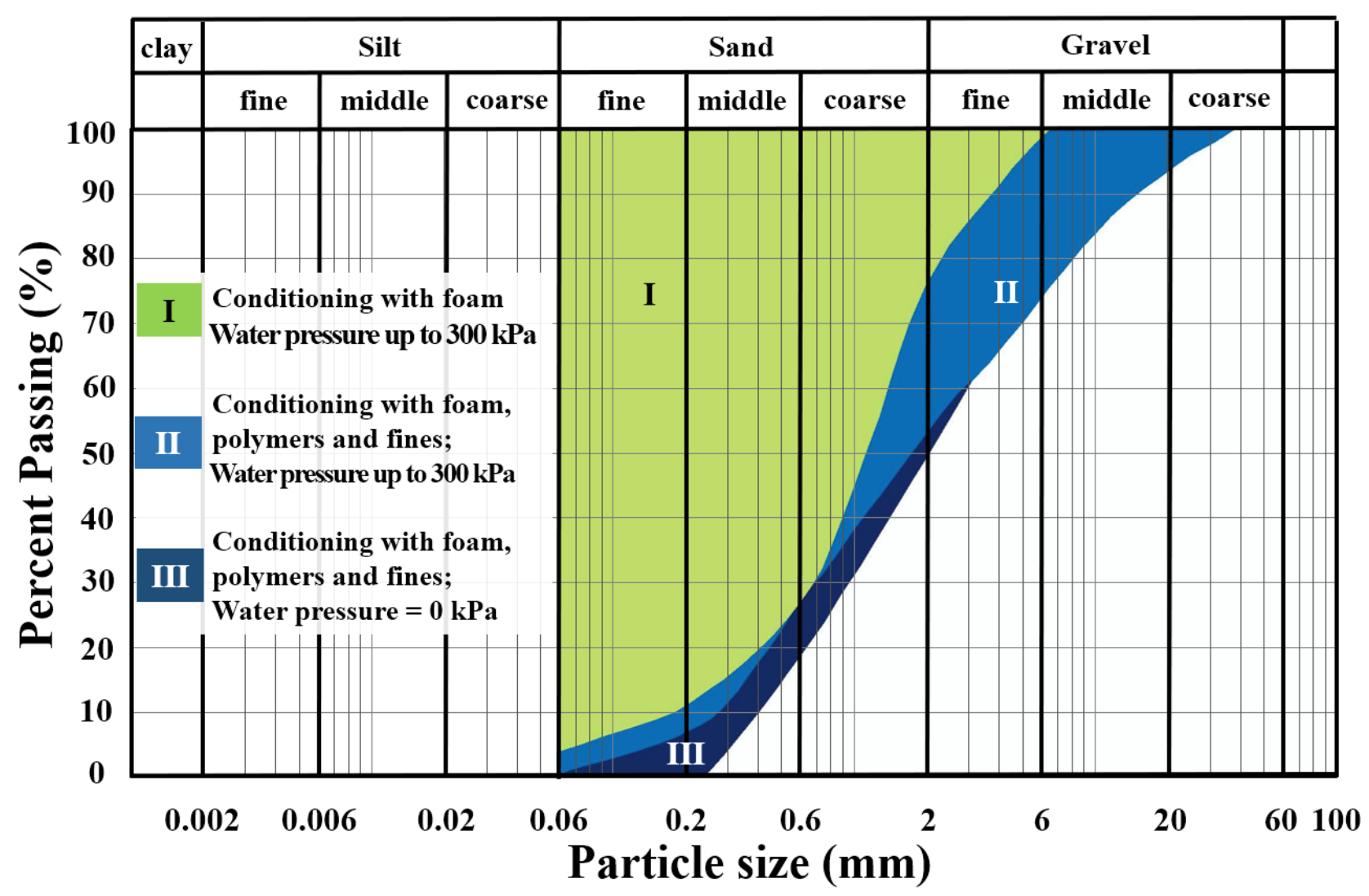

Figure 1. Choice of soil conditioning agent in earth pressure balance (EPB) shield tunnel boring machine (TBM) depending on particle-size gradation curves in coarse ground soil (Reprinted with permission from ref. [1].).

First, the particle-size gradation of the weathered granite soil has a wide spectrum of coarse to fine particles depending on the rock origin and weathering process; the characteristics of these soils are unique, neither sand nor clay. Second, the particle-crushing characteristics of the weathered granite soil appear to be more dominant than those of sand [11-13]. As such, the particle-size gradation curve of weathered granite soil changes after soil conditioning; in particular, the soil particle percentage that passes through a \#200 sieve increases after soil conditioning. Third, weathered granite soil has a complicated relationship with water that depends on the water content. The natural water content of the saturated granite soils (below the groundwater table) on the Korean peninsula are within the range of $11-21 \%$ in most cases [14]. Particle-crushing capacity increases if water is added to granite soils, increasing the compressibility and decreasing the shear strength [12]. Kim et al. [10] performed a preliminary study on choosing a soil conditioning agent using 
two types of weathered granite soils that were within the previously proposed application range of EPB shield TBM shown in Figure 1 proposed by [1]; the authors found that soils can be well-conditioned with only foam, that is, without polymers or fines, if the water content of the excavated soil is at optimal values. This research extended that preliminary research by [10] through the following comprehensive studies:

(1) More comprehensive ranges were studied of weathered granite soils having different particle-size gradation curves and percentages of fine particles (less than \#200 sieve size) ranging from $0 \%$ (extremely cohesionless soil) to $17.1 \%$.

(2) Upper and lower bounds of water content, as well as optimum contents dependent upon fine particle-size contents, were tested. If the water content of the excavated soil was more than the upper bound value, the slump value might be larger than $20 \mathrm{~cm}$, which is too fluidic; then, extracting the excavated soil through a screw conveyor may not feasible. If the water content is less than the lower bound value, then it is not feasible to achieve the slump value of $10 \mathrm{~cm}$ without adding water.

(3) Finally, application ranges of EPM shield TBM and choice of conditioning agents were determined for weathered granite soils; the ranges depend on the soil's water content. The ranges proposed in this study may differ from those proposed by [1], and one of the primary reasons for this difference might be the particle-crushing characteristics of weathered granite soil.

\section{Materials and Methods}

\subsection{Experimental Equipment and Process}

The experimental equipment and testing process are described in [10]. Among them, the most important equipment for performing conditioning agent mixing experiments using foam might be the foam generator. For this study, a laboratory-scale foam generator was produced that could control the foam expansion ratio (FER) and the foam injection ratio (FIR); see [10] for details. In this experiment, the initial water content of each weathered granite soil sample was set to $10 \%$, considering that the natural water content of saturated soil is more than $11 \%$ and less than $21 \%$ in most cases. Then, after foam was generated for each FIR, additional water was added up to the designated water content, and these were mixed together with an agitator. Immediately after mixing, slump, permeability, and compressibility were tested. In this permeability test, attention should be paid so that the filters installed both at the top and bottom of the sample are fully saturated before the test. Furthermore, since the foam itself may be drained for a long period of time, long-term changes in the permeability coefficient were observed over a longer period. For the detailed experimental methods of these three tests, please refer to [10].

\subsection{Weathered Granite Soils and Conditioning Agents Used in Experiments \\ 2.2.1. Weathered Granite Soils}

Five weathered granite soil samples were prepared, ranging from relatively fine to coarse; the particle-size gradation curves for these five samples are shown in Figure 2 (solid lines); properties of these five samples are shown in Table 1. As shown in Table 1, the percentage of fine particles passing through \#200 sieve changed from 17.1\% (for Soil 1) to nil (for Soil 5). After the experiments, sieve analysis was conducted again for the oven-dried samples to obtain the particle-size gradation curves in order to find the particlecrushing effect after soil conditioning; these are represented by the dotted lines in Figure 2. The particle-crushing effect is predominantly dependent upon the particle size of the soils. Figure 2 shows that the percentage of fine particles passing through \#200 sieve gradually increases with the increase of soil particle sizes (except for Soil 5, which is classified as gravel): increases of $3.7 \%$ for Soil 1, $4 \%$ for Soil 2, $4.7 \%$ for Soil 3, and as much as $5 \%$ for Soil 4. As can be seen from regions I, II, and III of Figure 1, fine particle contents in the gradation curve of soils are the most crucial factor when determining the conditioning agent in the EPB Shield TBM method. For this reason, the particle-crushing effect of the 
weathered granite soil must be taken into consideration when assessing the conditioning agent. This will be further discussed in Section 3.

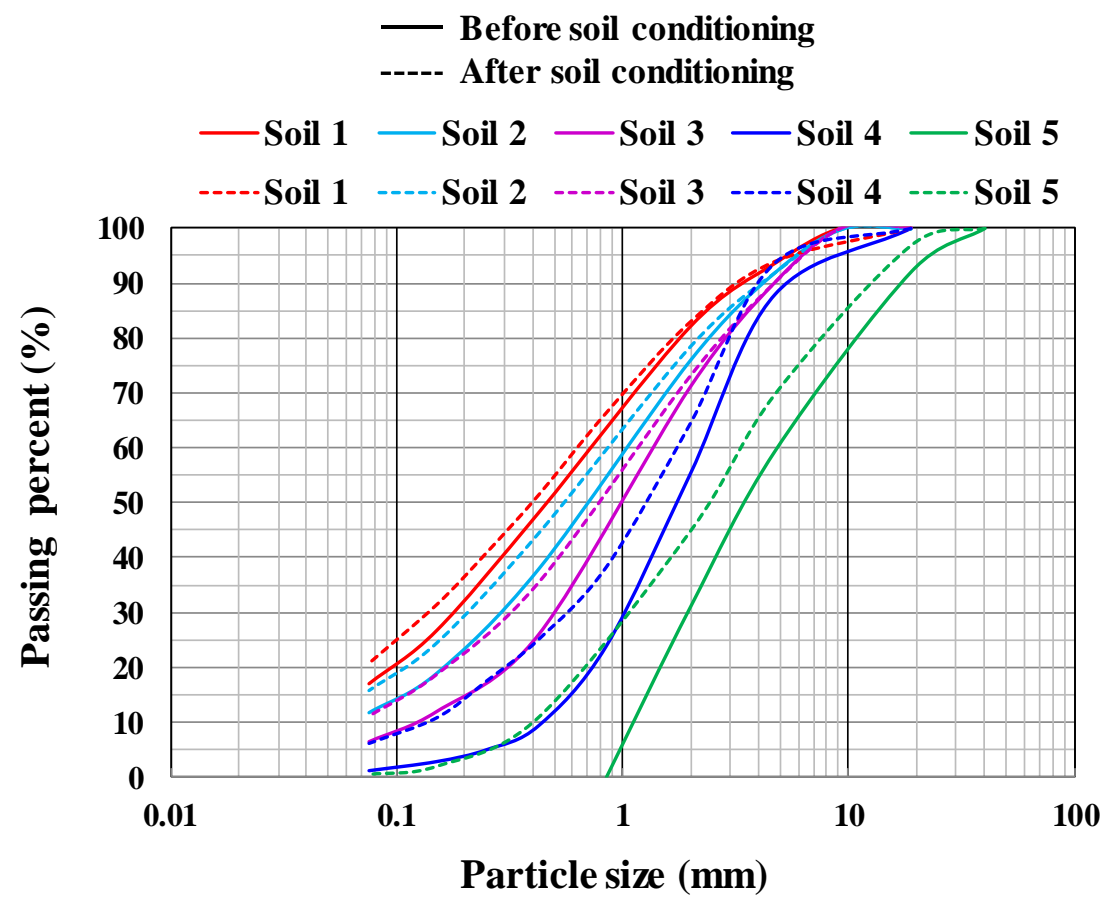

Figure 2. Particle-size gradation curves for the five weathered granite soils.

Table 1. Physical properties of the five weathered granite soils.

\begin{tabular}{cccccc}
\hline & Soil 1 & Soil 2 & Soil 3 & Soil 4 & Soil 5 \\
\hline $\begin{array}{c}\text { Percent passing through a } \\
\text { \#200 sieve (\%) }\end{array}$ & 17.1 & 11.8 & 6.5 & 1.2 & 10 \\
\hline Initial water content (\%) & 10 & 10 & 10 & 10 \\
\hline $\begin{array}{c}\text { Permeability coefficient } \\
(\mathrm{cm} / \mathrm{s})\end{array}$ & $2.93 \times 10^{-4}$ & $4.46 \times 10^{-4}$ & $9.13 \times 10^{-4}$ & $1.40 \times 10^{-3}$ & $1.80 \times 10^{-2}$ \\
\hline Consistency & $\mathrm{NP}$ & $\mathrm{NP}$ & $\mathrm{NP}$ & $\mathrm{NP}$ & 2.63 \\
\hline $\mathrm{G}_{\mathrm{s}}$ & 2.62 & 2.64 & 2.59 & $\mathrm{SP}$ & $\mathrm{SP}$ \\
\hline Unified classification & $\mathrm{SM}$ & $\mathrm{SP}-\mathrm{SM}$ & $\mathrm{SP}-\mathrm{SM}$ & & $\mathrm{SP}$ \\
\hline
\end{tabular}

\subsubsection{Conditioning Agents}

The conditioning agents used for the EPB shield TBM include water, foam, polymer, solidification agent (water-absorbing polymer), bentonite, and anti-clay polymer. The conditioning agents used in this experiment and their physical properties are summarized in Table 2. Foam added to the excavated soil plays roles in increasing compressibility, reducing the internal friction angle, maintaining the uniform distribution of the chamber pressure, and reducing the permeability [15]. In these experiments, an FER of 10 was used, which is a normal practice in situ [10].

Polymers are used in coarse soil with high permeability and/or when tunneling work is going on below the groundwater level. In other words, the use of polymers is recommended when mixing with foam alone is not sufficient. Soil-structuring polymer used in porous ground forms networks through chained structures to increase the cohesion of the excavated soil and reduce the internal friction angle $[15,16]$. As a result, the soilstructuring polymer helps the conditioned soil to behave in a pseudo-plastic state and 
decreases the soil's permeability. The polymer slurry used in these experiments was an emulsion type with high viscosity; it was diluted to $0.3 \%$ concentration before it was added to the soil samples. Polymer slurry can be injected either at the front of the cutter head or within the chamber, with or without other conditioning agents. In contrast, the polymer used as a solidification agent (known as water-absorbing polymers or thickeners) is not diluted but is directly added to the working chamber or the screw conveyor as is. By the way, for the definition of parameters to describe the quantity and quality of the conditioning agents such FER, FIR, and polymer injection ratio (PIR), please refer to [10].

Table 2. Properties of conditioning agents used in the experiment.

\begin{tabular}{cccc}
\hline Category & Foam & Polymer 1 & Polymer 2 \\
\hline Product name & MAK Foam & SUPER MUD (emusion) & MAK SOL-L (liquid) \\
Type & Foam & Polymer slurry & (solidification agent) \\
Property & Biodegradable surfactant & Polyacrylic acid polymer & Acrylates polymer \\
Density & $1.00-1.10$ & $1.00-1.10$ & $1.20-1.30$ \\
pH & $8-9$ & $7-9$ & $7-9$ \\
Concentration $(\%)$ & 2 & 0.3 & Undiluted solution \\
\hline
\end{tabular}

\section{Results and Discussion}

\subsection{Ranges of Water Content for Workability Requirement}

As mentioned in Section 1, in order to provide the desired workability for the EPB shield TBM operation, slump values of the conditioned soils should be between $10 \mathrm{~cm}$ and $20 \mathrm{~cm}$. Kim et al. [10] mentioned that controlling the water content inside the working chamber is as important as controlling the FIR.

Figure 3 shows typical measured slump values with different water contents and FIRs for the four soil samples (Soil 1 to 4) in Figure 2 and Table 1; pictures taken after slump tests are shown in Figure 4. The FIRs varied from small (22\%) to large (88\%); the normal range is $30 \%$ to $80 \%$. Referencing the experimental results of Figure 3a, slump tests were not conducted thereafter if we expected the slump values to either exceed $20 \mathrm{~cm}$ or be much less $10 \mathrm{~cm}$ (please see missing data in Figure 3b,d).

For each sample, the water content that reached the slump value of as small as $10 \mathrm{~cm}$ was obtained in spite of adding foam with the maximum FIR of $88 \%$ was designated the lower bound of water content. On the contrary, the water content that reached the slump value as large as $20 \mathrm{~cm}$ was obtained in spite of adding foam with the minimum FIR of $22 \%$ was designated the upper bound of water content. These results are summarized in Figure 5; the figure shows the upper and lower bounds of water content for slump values of $10-20 \mathrm{~cm}$ as a function of the percentage of fine particles in excavated soil passed through a \#200 sieve (from $1.2 \%$ to $17.1 \%$ ).

As shown in Figure 5, the water content to reach the slump values of $10 \mathrm{~cm}$ to $20 \mathrm{~cm}$ increased as the fine particle content increased. Curve A in Figure 5, indicating the median between the lower and upper bounds, might represent the optimum water contents as a function of the fine particle content passing through the \#200 sieve. From this figure, the following strategy for choosing a soil conditioning agent can be proposed.

(1) If the water content of the excavated soil is within the allowable range proposed in Figure 5, the workability requirement is satisfied with slump values between $10 \mathrm{~cm}$ and $20 \mathrm{~cm}$. In this case, we have to check whether the conditioned soils also satisfy the permeability and compressibility requirements; if these are satisfied, it is sufficient to add only foam as the soil conditioning agent. This will be further discussed in Section 3.2

(2) If the water content of the excavated soil is below the lower bound values, the workability requirement for slump value greater than $10 \mathrm{~cm}$ will not be satisfied; water must be added to the working chamber to reach the optimum values shown on curve A. 
(3) If the water content is above the upper bound shown in Figure 5, the workability requirement for slump value less than $20 \mathrm{~cm}$ will not be satisfied, requiring added solidification agents in addition to foams. This will be discussed in Section 3.3.1.

(4) Finally, if the weathered granite soil is extremely coarse and cohesionless with fine particle percentage less than $1.2 \%$ (Soil 5 in Table 1), the particle-size gradation curve shown in Figure 2 is located outside (to the right) of the applicable ranges proposed by [1] (see Figure 1). To take advantage of the particle-crushing characteristics of weathered granite soil, it may be necessary to check the feasibility of applying the EPB shield TBM in this outside region also. Additional conditioning agents such as polymer slurries and/or solidification agents (water-absorbing polymers) may be required in this region in addition to foams. This will be discussed in Section 3.3.2.

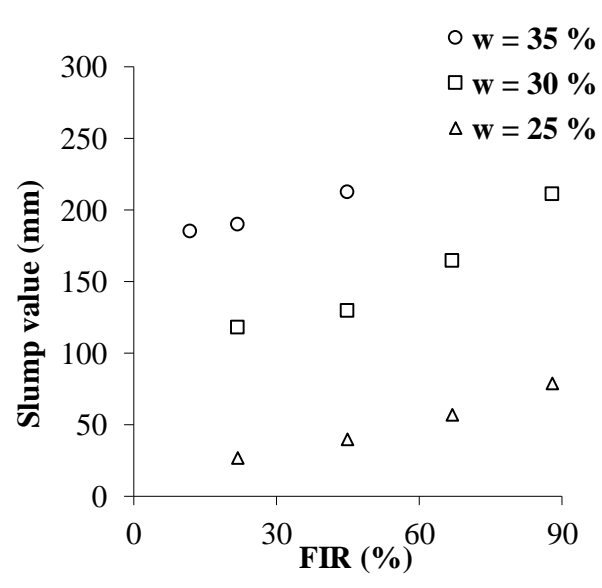

(a)

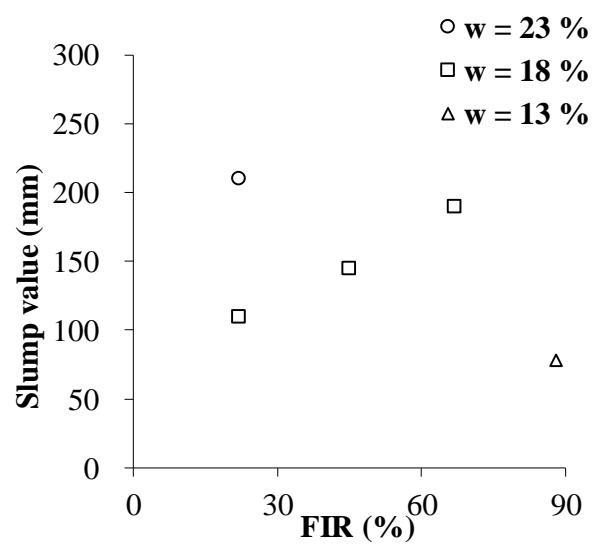

(c)

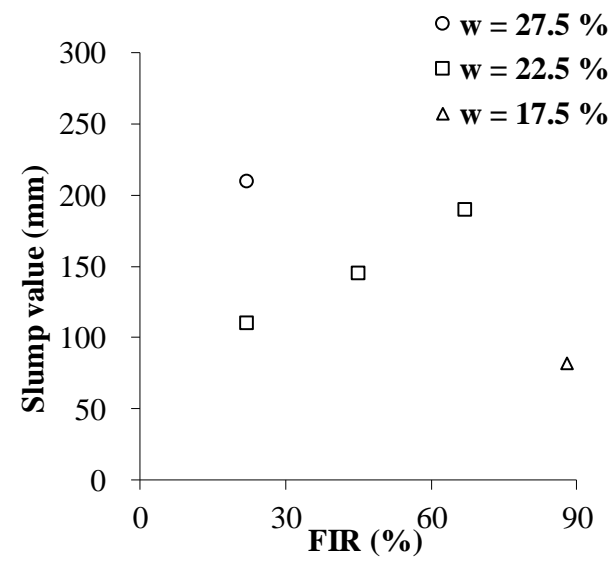

(b)

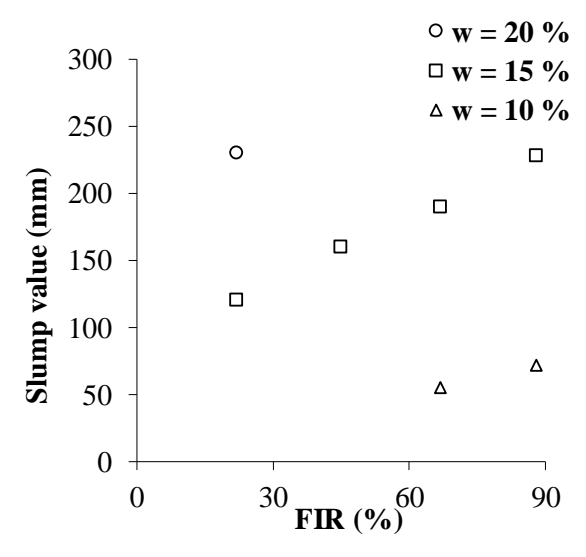

(d)

Figure 3. Slump values with variation in the water content and foam injection ratio (FIR) [10]: (a) Soil 1, (b) Soil 2, (c) Soil 3, (d) Soil 4.

\subsection{Optimal Mixing Ratio of Conditioning Agents: With Foam Only}

As mentioned in the previous section, if the water content in the working chamber is controlled within the allowable ranges proposed in Figure 5, the workability of the excavated soils will be satisfied by conditioning using foam only. Permeability and compressibility tests were performed on the soil samples conditioned with foam (Soil 1 through Soil 4), in which the water contents were controlled within allowable ranges. Since Kim et al. [10] revealed in their preliminary study that soils conditioned with foam satisfy all the requirements when FIR can be controlled between $22 \%$ and $67 \%$ in the optimum water contents shown in curve A in Figure 5, in this study, all the tests were done under the same 
conditions. Experimental results are summarized in Table 3; the table shows that as the FIR increased, the permeability coefficient decreased while the compressibility increased as well. Table 3 shows that all the conditioned soil samples met the three requirements: slump value between $10 \mathrm{~cm}$ and $20 \mathrm{~cm}$, permeability coefficient less than $1 \times 10^{-3} \mathrm{~cm} / \mathrm{s}$, and compressibility more than $1.9 \% / 0.5$ bar.

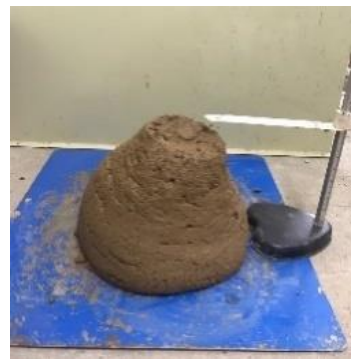

FIR $22 \%$

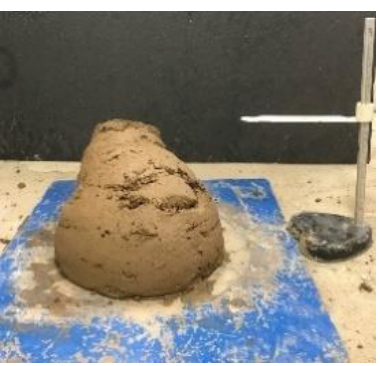

FIR $22 \%$

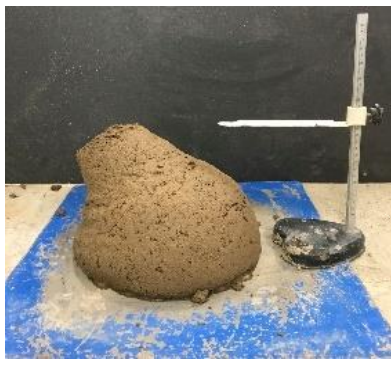

FIR $22 \%$

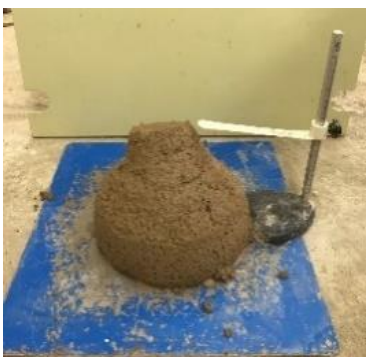

FIR $22 \%$

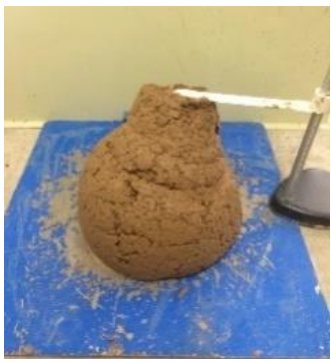

FIR $45 \%$

(a)

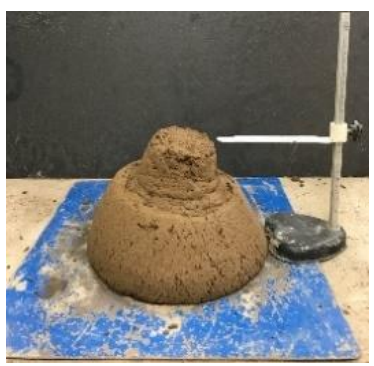

FIR 45\%

(b)

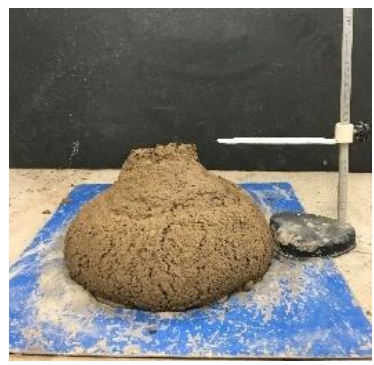

FIR 45\%

(c)

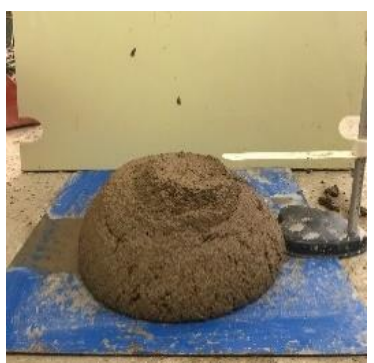

FIR 45\%

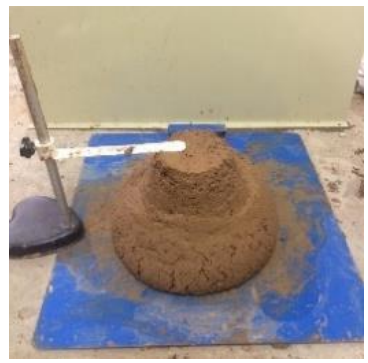

FIR 67\%

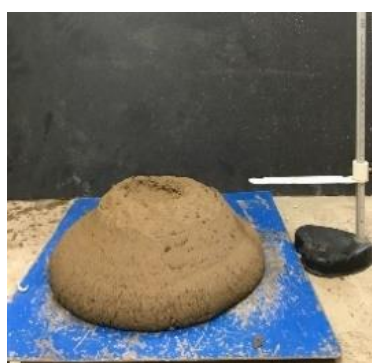

FIR 67\%

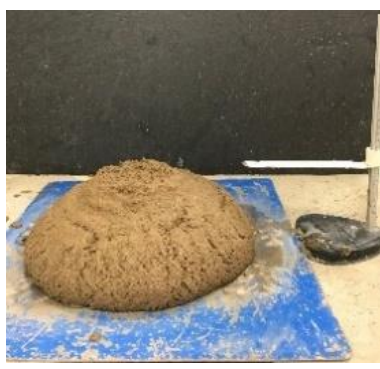

FIR 67\%

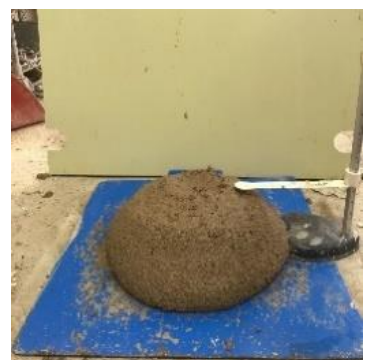

FIR 67\%

(d)

Figure 4. Slump test results with variation in the water content and FIR [10]: (a) Soil 1 (water content $=30 \%$ ), (b) Soil 2 (water content $=22.5 \%$ ), (c) Soil 3 (water content $=18 \%$ ), (d) Soil 4 (water content $=15 \%)$. 


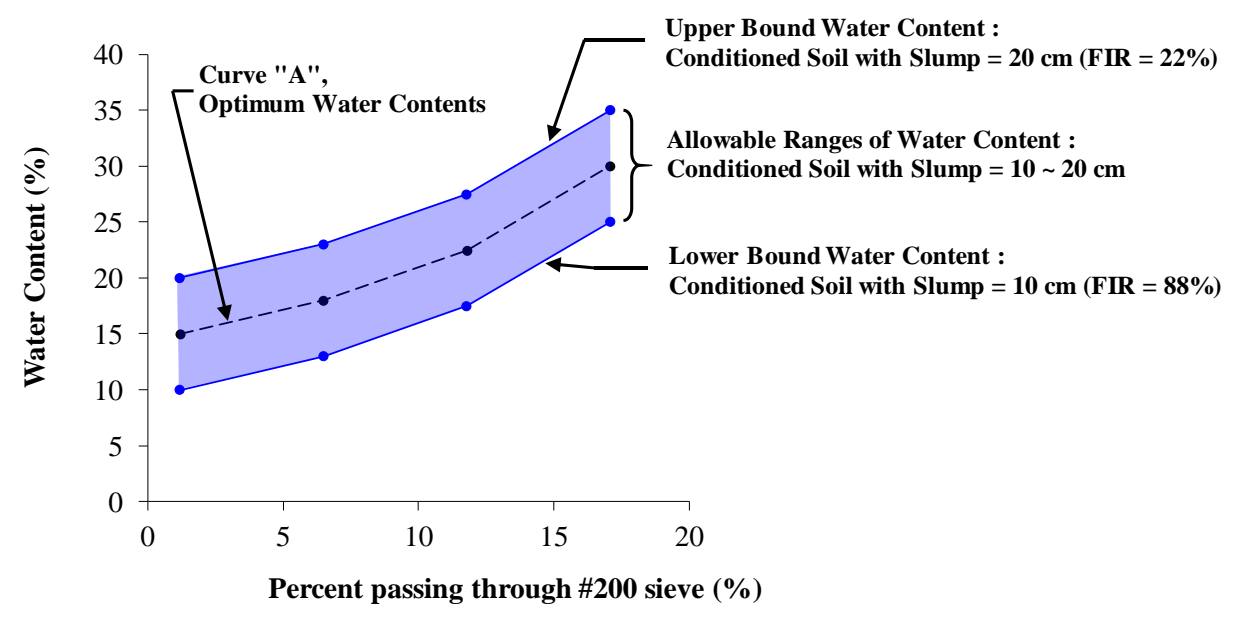

Figure 5. Allowable water contents and upper/lower bounds depending on fine particle contents.

Table 3. Properties of conditioned soils depending on foam mix ratios.

\begin{tabular}{|c|c|c|c|c|c|c|}
\hline Soil & FER & FIR (\%) & w (\%) & Slump (cm) & $\begin{array}{c}\text { Permeability } \\
\text { Coefficient }(\mathrm{cm} / \mathrm{s})\end{array}$ & $\begin{array}{l}\text { Compressibility } \\
\text { (\%/0.5 Bar) }\end{array}$ \\
\hline Weathered & 0 & 0 & 10 & None & $2.93 \times 10^{-4}$ & 0.48 \\
\hline Granite Soil 1 & 10 & 22 & 30 & 11.8 & - & 3.18 \\
\hline$(\# 200$ finer $=$ & 10 & 45 & 30 & 13 & - & 4.36 \\
\hline $17.1 \%)$ & 10 & 67 & 30 & 16.5 & - & 5.02 \\
\hline Weathered & 0 & 0 & 10 & None & $4.46 \times 10^{-4}$ & 0.38 \\
\hline Granite Soil 2 & 10 & 22 & 22.5 & 11 & - & 3.02 \\
\hline$(\# 200$ finer $=$ & 10 & 45 & 22.5 & 14.5 & $1.98 \times 10^{-6}$ & 4.16 \\
\hline $11.8 \%)$ & 10 & 67 & 22.5 & 19 & - & 4.98 \\
\hline Weathered & 0 & 0 & 10 & None & $9.13 \times 10^{-4}$ & 0.29 \\
\hline Granite Soil 3 & 10 & 22 & 18 & 11.5 & - & 2.90 \\
\hline$(\# 200$ finer $=$ & 10 & 45 & 18 & 15 & $2.73 \times 10^{-6}$ & 4.12 \\
\hline $6.5 \%)$ & 10 & 67 & 18 & 19.5 & - & 4.86 \\
\hline Weathered & 0 & 0 & 10 & None & $1.40 \times 10^{-3}$ & 0.24 \\
\hline Granite Soil 4 & 10 & 22 & 15 & 12 & $2.16 \times 10^{-6}$ & 2.74 \\
\hline$(\# 200$ finer $=$ & 10 & 45 & 15 & 16 & $1.62 \times 10^{-6}$ & 4.04 \\
\hline $1.2 \%)$ & 10 & 67 & 15 & 19 & $1.17 \times 10^{-6}$ & 4.84 \\
\hline
\end{tabular}

The measured permeability coefficient summarized in Table 3 is the initial measurement value; however, at the job site, it would be necessary to maintain this low coefficient for at least $90 \mathrm{~min}$ to provide good workability during ring assembly and other processes [3]. Therefore, the change of permeability coefficients with elapse of time was monitored up to $10 \mathrm{~h}$; monitored results are shown in Figure 6. The figure shows that even though the permeability coefficients tended to increase with time, the final values were still far below $1 \times 10^{-3} \mathrm{~cm} / \mathrm{s}$.

In summary, in weathered granite soil with fine particles at least $1.2 \%$, the excavated soils can be conditioned with foam alone as long as the water contents are controlled within the allowable values (and preferably the optimal values) shown in Figure 5 and the conditioned FIR is controlled within the range of $22 \%$ to $67 \%$.

\subsection{Optimal Mixing Ratio of Conditioning Agents: With Foam and Polymer}

\subsubsection{Conditioning with Foam and Water-Absorbing Polymer}

As mentioned in Section 3.1, if the water content in excavated soil exceeds the upper bound shown in Figure 5, the workability requirement of slump value less than $20 \mathrm{~cm}$ will not be satisfied; solidification agents need to be added in addition to foam. Therefore, a series of tests were performed on excavated soils in which water contents exceeded the 
upper bound shown in Figure 5. In these tests, all the soil samples were conditioned with foam added at a minimum FIR of $22 \%$ and with and without adding the water-absorbing polymer; typical results are shown in Figure 7.

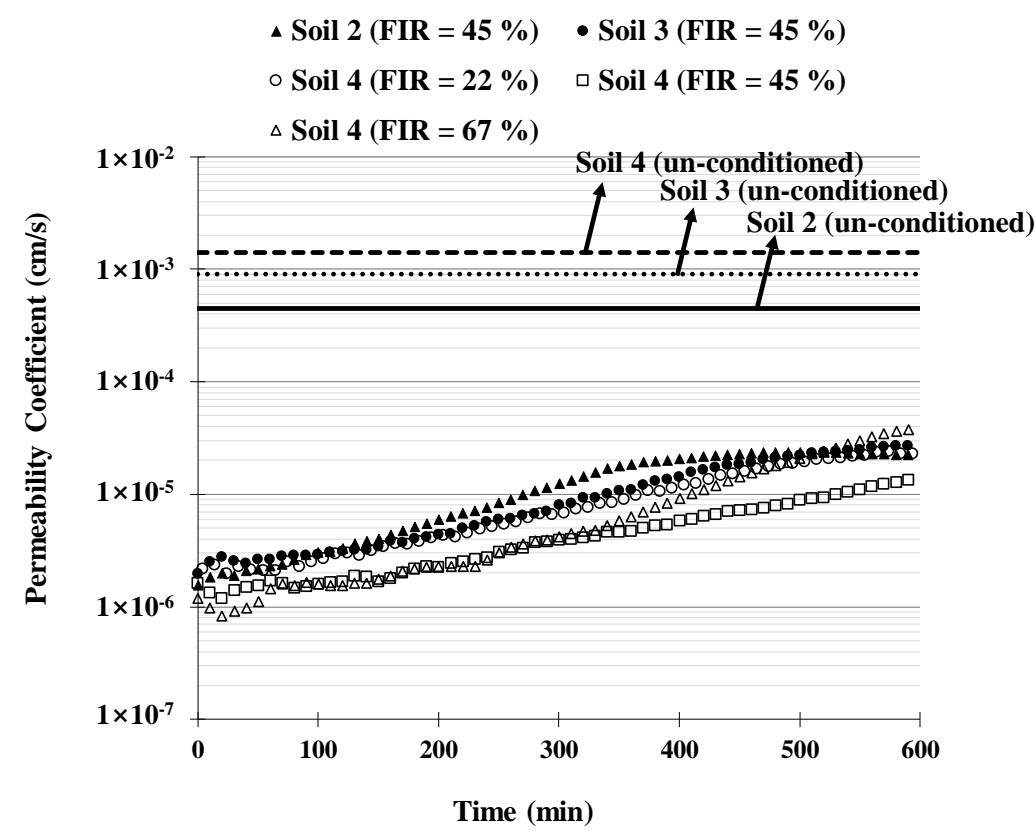

Figure 6. Permeability coefficient changes of conditioned soils with elapse of time (Soil 2-4).

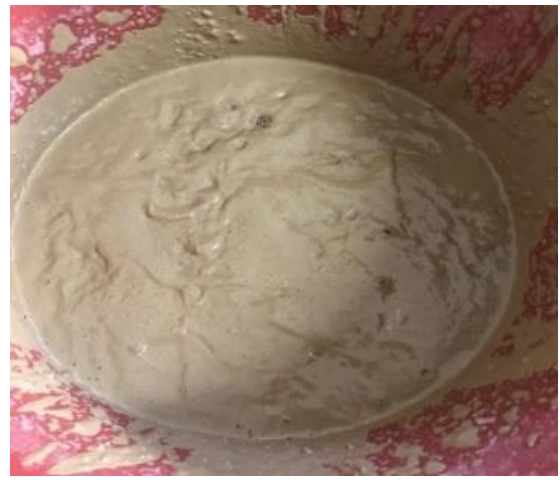

(a)

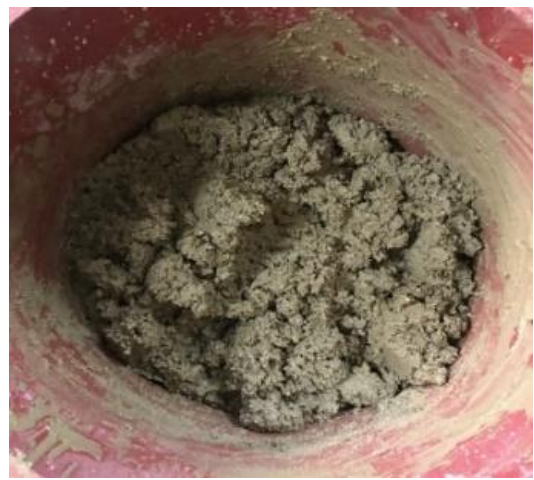

(b)

Figure 7. Samples conditioned with and without adding water-absorbing polymer in addition to foam: (a) foam only, (b) foam and water-absorbing polymer.

When only foam was added, the soil samples were too fluidic, whereas when both foam and water-absorbing polymer are added together, the conditioned soil appears to be in a plastic state. Experimental results are summarized in Table 4; the table shows that if only foam was added as a conditioning agent, the soil samples appeared to be too fluidic to measure the slump value. However, when water-absorbing polymer (not diluted) was added along with foam, we were able to match the slump value requirement of $10 \mathrm{~cm}$ to $20 \mathrm{~cm}$; please see Figure 8 showing pictures of soil samples taken after slump tests. The "N/107.8 N" in Table 4 indicates the amount (in Newtons) of water-absorbing polymer injected into the conditioned soil with the amount of $107.8 \mathrm{~N}$. 
Table 4. Properties of conditioned soils depending on added amount of water-absorbing polymer.

\begin{tabular}{|c|c|c|c|c|c|}
\hline Soil & FIR (\%) & w (\%) & $\begin{array}{c}\text { Water-Absorbing } \\
\text { Polymer/Excavated Soil } \\
\text { (N/107.8 N) }\end{array}$ & Slump (cm) & $\begin{array}{c}\text { Compressibility } \\
\text { (\%/0.5 Bar) }\end{array}$ \\
\hline Soil 1 & 22 & 36.5 & 0 & Too fluidic & 3.18 \\
\hline$(\# 200$ finer $=17.1 \%)$ & 22 & 36.5 & 0.38 & 14 & 2.70 \\
\hline Soil 2 & 22 & 28 & 0 & Too fluidic & 3.02 \\
\hline$(\# 200$ finer $=11.8 \%)$ & 22 & 28 & 0.39 & 15 & 2.52 \\
\hline Soil 3 & 22 & 24 & 0 & Too fluidic & 2.90 \\
\hline$(\# 200$ finer $=6.5 \%)$ & 22 & 24 & 0.38 & 14.5 & 2.44 \\
\hline \multirow{4}{*}{$\begin{array}{c}\text { Soil } 4 \\
(\# 200 \text { finer }=1.2 \%)\end{array}$} & 22 & 21 & 0 & Too fluidic & 2.75 \\
\hline & 22 & 21 & 0.34 & 19 & 2.40 \\
\hline & 22 & 21 & 0.39 & 14.5 & 2.20 \\
\hline & 22 & 21 & 0.44 & 12 & 2.02 \\
\hline
\end{tabular}
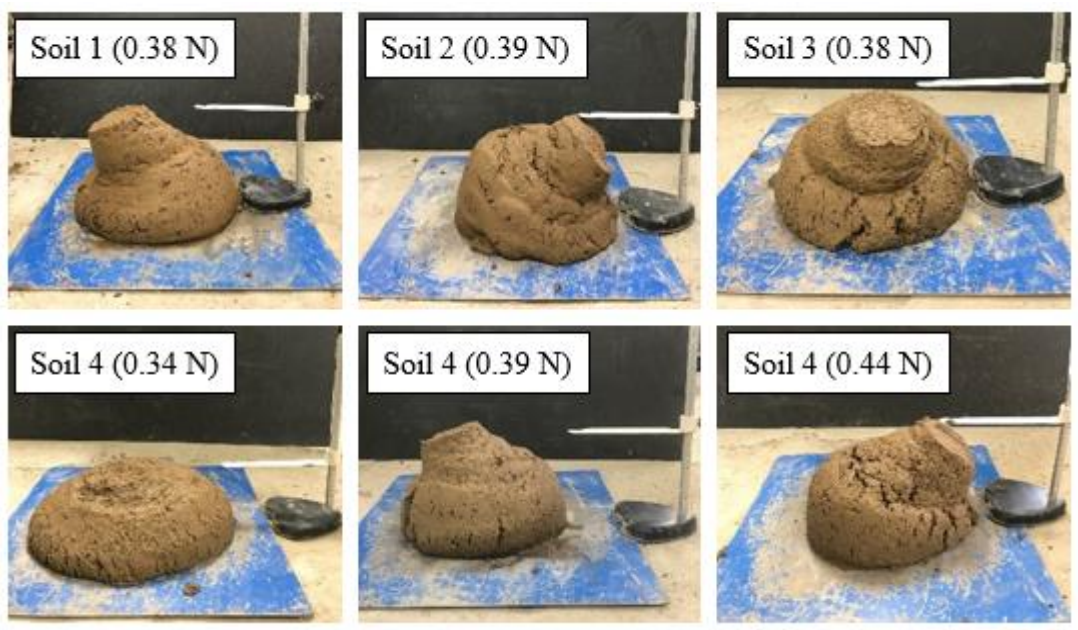

Figure 8. Soil samples after slump tests at varying amounts of added water-absorbing polymers.

Even though it was observed that the compressibility decreased (slightly reduced by adding the water-absorbing polymers by up to $26 \%$ ), these values were still larger than the required $1.9 \% / 0.5$ bar. In summary, excavated soils with water contents above the upper bound values proposed in Figure 5 can meet the workability, permeability, and compressibility requirements if they are conditioned with foam added at approximately $22 \%$ FIR and around $0.39 \mathrm{~N}$ of water-absorbing polymer per $107.8 \mathrm{~N}$ of excavated soil.

\subsubsection{Conditioning with Foam and Multiple Polymer}

If the weathered granite soil is extremely cohesionless (coarse) with fine particle percentage less than $1.2 \%$ (Soil 5 in Table 1), the particle-size gradation curve shown in Figure 2 is located outside (to the right) of the applicable ranges proposed by [1], as mentioned in Section 3.1. In other words, according to their proposal, the EPB shield TBM cannot be adopted in this region. However, to take advantage of the particle-crushing characteristics of weathered granite soil, the feasibility should be checked of applying the EPB shield TBM in this region also. However, the region may need additional conditioning agents such as water-absorbing polymers or polymer slurries in addition to foam.

A series of tests were performed on Soil 5 shown in Figure 2 and Table 1, in which the fine particle content was zero. As the conditioning agents, foam was added at FIRs ranging from $22 \%$ to $67 \%$ with and without polymer slurry added at PIRs ranging from $8 \%$ to $30 \%$. The optimal water content was obtained following trial and error; to satisfy the workability requirement of slump value between 10 and $20 \mathrm{~cm}, 10 \%$ water content 
was used. Experimental results are summarized in Table 5, and pictures of the slump test results are shown in Figure 9. Table 5 shows that even though the slump value and compressibility requirements were satisfied by adding foam only at FIR of $45 \%$, it was not possible to meet the permeability requirement (slump requirement was not satisfied with FIR $=67 \%$; compressibility requirement was not satisfied with FIR $=22 \%$ ). Soil 5 was too porous to reduce the permeability coefficient to the thrust value of $1 \times 10^{-3} \mathrm{~cm} / \mathrm{s}$ with only foam.

Table 5. Properties of conditioned Soil 5 depending on the mixing ratios of conditioning agents.

\begin{tabular}{|c|c|c|c|c|c|c|}
\hline & W (\%) & FIR (\%) & PIR (\%) & Slump (cm) & $\begin{array}{l}\text { Compressibility } \\
\text { (\%/0.5 Bar) }\end{array}$ & $\begin{array}{c}\text { Permeability } \\
\text { Coefficient }(\mathrm{cm} / \mathrm{s})\end{array}$ \\
\hline \multirow{3}{*}{$\begin{array}{c}\text { Foam } \\
\text { conditioning }\end{array}$} & 10 & 22 & 0 & 12 & 1.22 & - \\
\hline & 10 & 45 & 0 & 16 & 2.67 & $1.17 \times 10^{-3}$ \\
\hline & 10 & 67 & 0 & 22 & 3.90 & - \\
\hline Foam and & 10 & 22 & 8 & 18 & 2.07 & $1.67 \times 10^{-4}$ \\
\hline Polymer slurry & 10 & 22 & 15 & 16 & 1.72 & $1.87 \times 10^{-4}$ \\
\hline conditioning & 10 & 22 & 30 & - & - & - \\
\hline
\end{tabular}
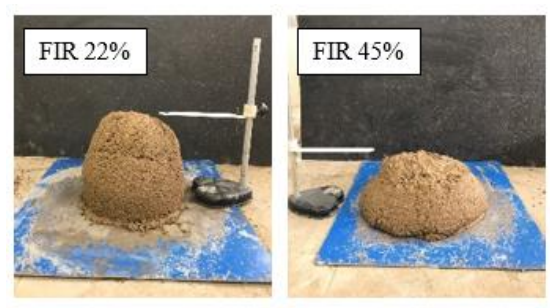

(a)
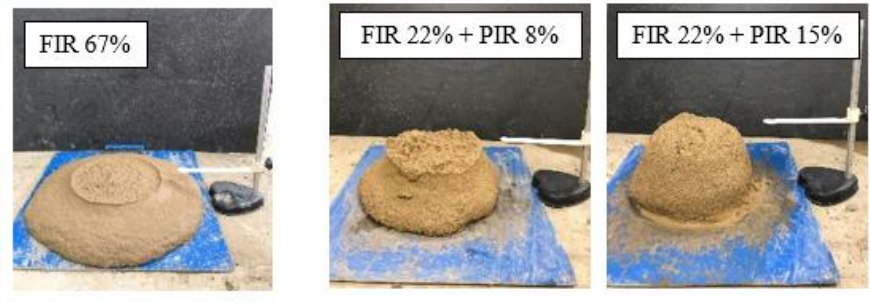

(b)

Figure 9. Slump test results depending on added conditioning agents: (a) Foam conditioning only, (b) Foam and polymer slurry conditioning.

As can be observed from the appearance of the conditioned soil in Figure 9a, foam and soil did not interact as a fully mixed material. The foam segregated from the soil, moved upward when tamped with a tamping rod to prepare for the slump tests, and finally flowed out from the soil samples as shown in Figure 9a. This segregation behavior between foam and excavated soil might reduce compressibility and/or impede reducing permeability.

Table 5 also presents the experimental results when the soil samples were conditioned with both foam and polymer slurry. Since the compressibility requirement can be easily met by adding polymer slurries, the minimum FIR was chosen to be $22 \%$. The PIR of the polymer slurry (concentration of $0.3 \%$ ) was varied from $8 \%$ to $30 \%$. The table shows that the slump value requirement was satisfied when the PIR was either $8 \%$ or $15 \%$. However, foam and polymer outflow were observed during the slump test, as can be seen in Figure $9 \mathrm{~b}$ when the PIR was at a higher value of $15 \%$. The segregation behavior also reduces the compressibility of the conditioned soil. At PIR of $30 \%$, the foam and the polymer experienced more serious material segregation during the slump test, and the specimen collapsed (see Figure 9b). This means that the plastic behavior of excavated soils is disrupted when excess polymer slurry is used.

In contrast, when the polymer slurry was added at PIR of $8 \%$, the compressibility increased; this was because the highly viscous polymer slurry trapped the foam so that it did not flow out from the soil sample. In other words, the polymer slurry changed the rheology of the excavated soils, preventing the segregation behavior [16]. Table 5 and Figure 10 show that the soils conditioned by adding foam at FIR $=22 \%$ together with polymer slurry at $\mathrm{PIR}=8 \%$ or $15 \%$ met the required permeability coefficient of $1 \times 10^{-3} \mathrm{~cm} / \mathrm{s}$. 


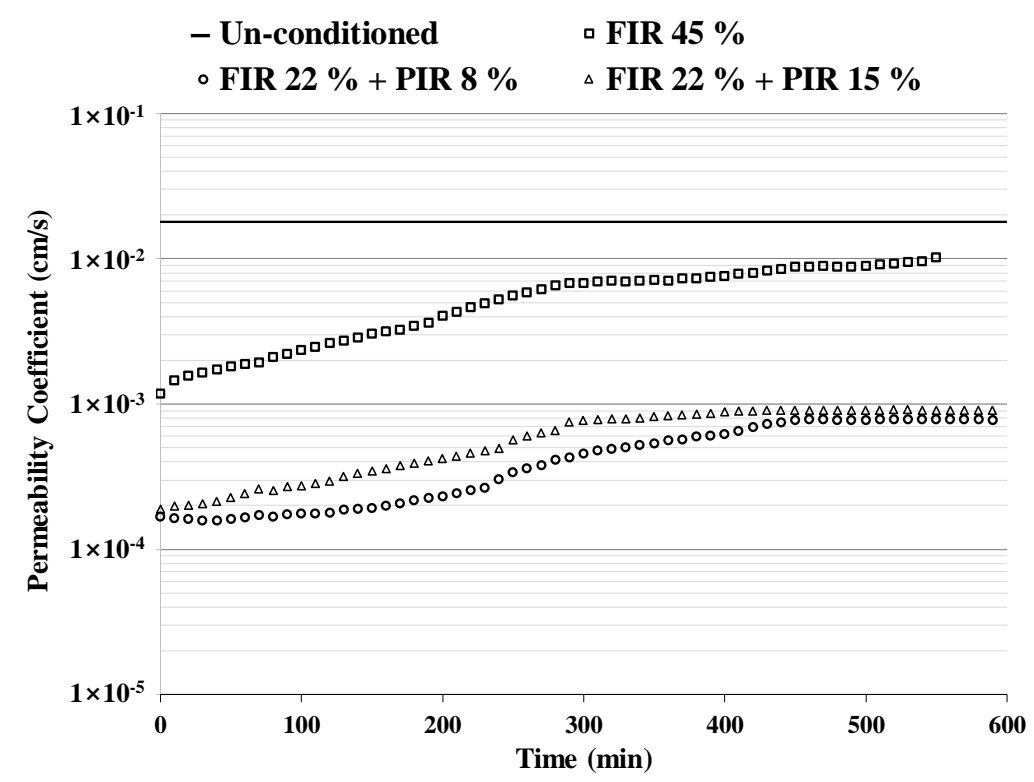

Figure 10. Permeability coefficient changes of the conditioned Soil 5 with elapse of time.

In summary, the conditioned soils satisfied all the requirements when conditioned with foam at $22 \%$ and polymer slurry at $8 \%$ as long as the water content in the chamber could be controlled at around $10 \%$. However, as we mentioned in the introduction, the natural water content of the saturated granite soils (below the groundwater table) on the Korean Peninsula are within the range of $11-21 \%$ in most cases [14]. In the laboratory experiments, it was not easy to prepare soil samples for slump tests (even when polymer slurry was added along with foam) if the water content was greater than $10 \%$. Since the water content was mostly greater than $11 \%$, it might be necessary to add solidification agents along with foam and polymer slurry for tunnels excavated below the groundwater table.

It is concluded that the EPB shield TBM is feasible even though weathered granite soil is extremely coarse (cohesionless) and exceeds the applicable boundaries proposed by [1]. However, the process requires conditioning with foam, polymer slurry, and/or water-absorbing polymers, and it is necessary to test different conditions through trial and error to produce soils that meet the three requirements or workability, compressibility, and permeability requirements.

Finally, a flow chart describing the process of how to choose a suitable conditioning agent is prepared as shown in Figure 11 so that readers can easily follow the process by themselves.

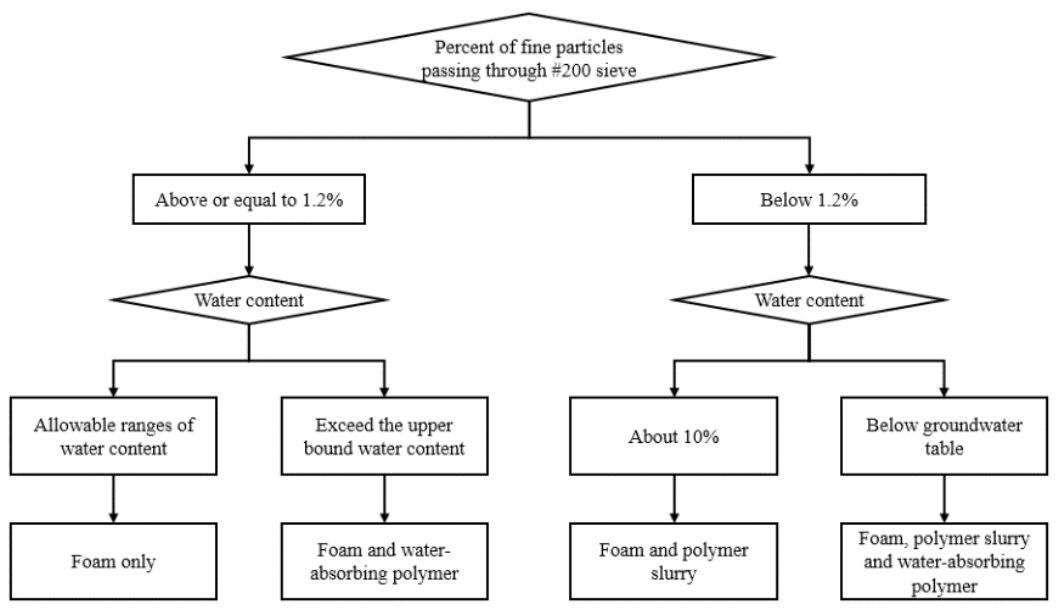

Figure 11. Soil conditioning agent selection for EPB shield TBM in weathered granite soil. 


\section{Application Ranges of EPB Shield TBM in Weathered Granite Soil Ground}

Figure 1 shows the application ranges of the EPB shield TBM proposed by [1], composed of three zones. As shown in the figure, soil conditioning with foam is possible in Zone I; however, in Zones II and III where the particle sizes are larger, that is, the soil is coarser, it is necessary to add polymers and fines in addition to foam to increase fine particle content and induce plasticity. By taking advantage of the particle-crushing effect of weathered granite soil and considering the findings presented here, new application ranges are proposed that are directly applicable to weathered granite soil. These are shown in Figure 12; the range proposed by [1] is presented in the same figure for comparison purposes.

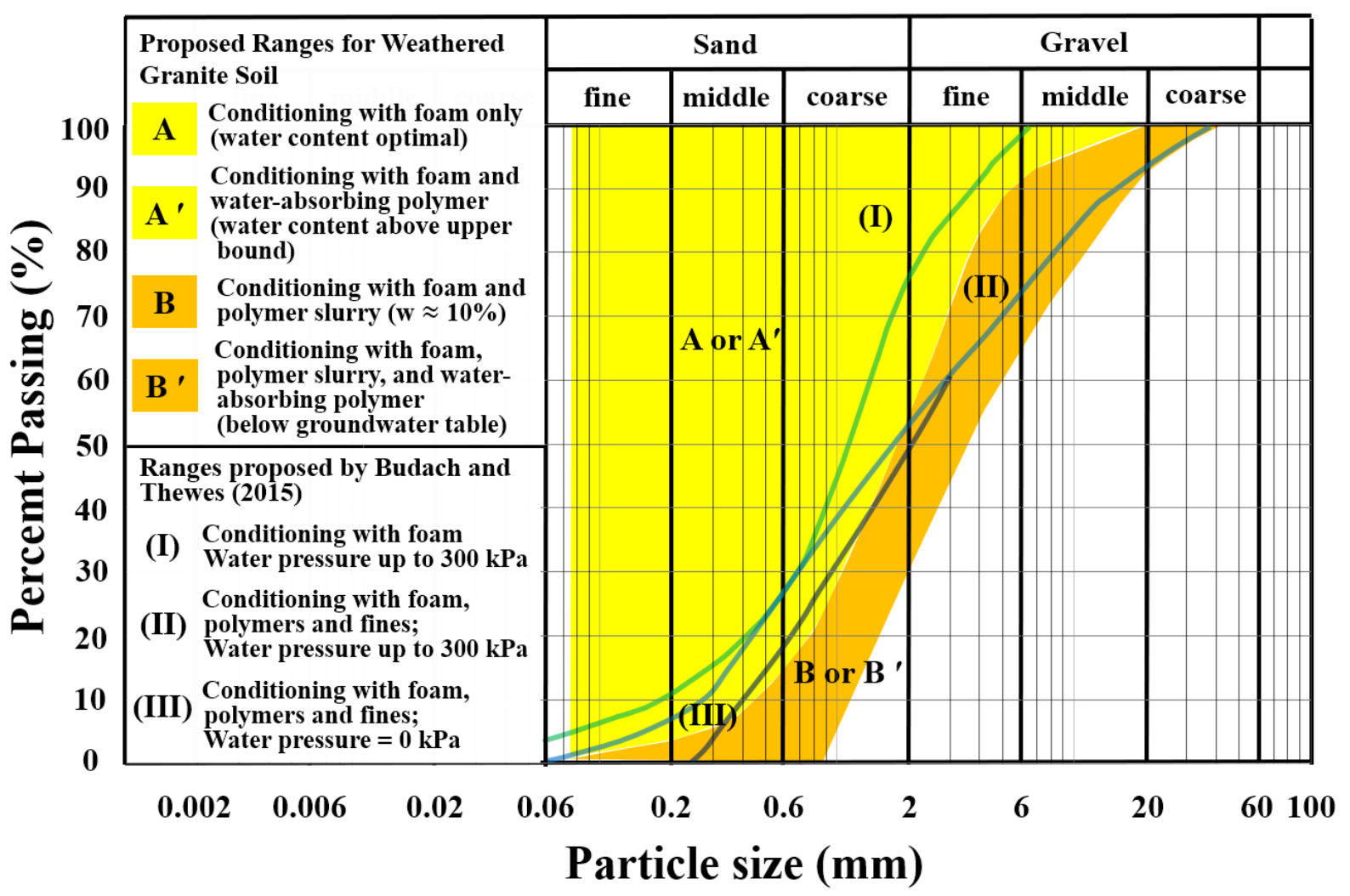

Figure 12. Application ranges of EPB shield TBM in weathered granite soil ground.

First, the ranges are divided into two categories by water content: A and $\mathrm{B}$ when the content is within the allowable range and $\mathrm{A}^{\prime}$ and $\mathrm{B}^{\prime}$ when the water content is excessive. Zone A (yellow area) in Figure 12 represents the region in which only foam is added for soil conditioning because the water content is within the allowable range (preferably the optimal value) shown in Figure 5; Zone A' (yellow area) in Figure 12 represents the region in which water-absorbing polymer was needed along with the foam because of water content of excavated soil above the upper bound shown in Figure 5.

Zone B (orange-colored area) represents the region in which polymer slurry is needed for soil conditioning in addition to foam when the water content is controlled at around $10 \%$; Zone $\mathrm{B}^{\prime}$ (orange-colored area) represents the region in which foam, polymer slurry, and thickening agent are needed for soil conditioning for digging out tunnels below the groundwater table (water contents larger than $10 \%$ ).

The application ranges proposed in Figure 12 can be used even if the water content of the excavated soil is less than the lower bound shown in Figure 5 in Zone A; however, it is important to add water to the chamber so that water content can reach the allowable range and preferably the optimum value shown on curve A in Figure 5. Similarly, in Zone $\mathrm{B}$, if the ground is only partially saturated, water must be added to reach $10 \%$. 
Figure 12 clearly shows that both zones expand more toward the right (coarser soil) than do the zones proposed by [1]. The main reason for the expanded application range could be the particle-crushing effect of the weathered granite soil, which moves the particlesize gradation curve of the excavated soil to the left after soil conditioning.

\section{Conclusions}

Soil conditioning methods applicable to the EPB shield TBM when the ground is composed of weathered granite soils were studied in this paper; the properties of the conditioned soils, i.e., workability (slump value), permeability, and compressibility, were evaluated in laboratory scale to find the optimum conditioning methods depending on soil water content. Application ranges of the EPB shield TBM in weathered granite soil were then proposed. The study conclusions are as follows.

Controlling water content to within the allowable range (see Figure 5) is the most important factor for successful EPB shield TBM operation. Optimal (or at least allowable) water content increased with increasing fine particle content in the soil.

It was found that if the water content of excavated soil is well controlled within the allowable range (see Figure 5) and the fine particle content finer than \#200 sieve size is more than $1.2 \%$, soil can be conditioned with foam only with an optimal FIR range of $22-67 \%$. However, if water content exceeds the upper bound, water-absorbing polymer (solidification agent) should be added in addition to foam to change fluidic soils to plastic.

Even with extremely coarse weathered granite soil (fine particle content less than $1.2 \%$ ), the EPB shield TBM can still be adopted; however, polymer slurry (and additional water-absorbing polymer when digging out tunnels below the groundwater table) should be added with foam to change the cohesionless state of the soil to sticky or plastic.

Application ranges of the EPB shield TBM of the weathered granite soil proposed in this study revealed that ranges were more expanded to the right (coarser) side compared with those proposed by [1]. The main reason for the expanded application range might be the particle-crushing effect of the weathered granite soil, which moves the particle-size gradation curve of the excavated soil to the left after soil conditioning.

Author Contributions: Conceptualization, T.-H.K. and I.-M.L.; Formal analysis, T.-H.K.; Funding acquisition, I.-M.L. and J.-J.P.; Investigation, T.-H.K., H.-Y.C. and Y.-M.R.; Methodology, T.-H.K.; Project administration, T.-H.K. and I.-M.L.; Writing—original draft, T.-H.K.; Writing-review and editing, I.-M.L. and Y.-M.R. All authors have read and agreed to the published version of the manuscript.

Funding: This work was supported by the National Research Foundation of Korea (NRF) grant funded by the Ministry of Science and ICT of Korean government (MIST) (No. 2019R1C1C1008326) and Infrastructure and Transportation Technology Promotion Research Program funded by the Ministry of Land, Infrastructure and Transport of Korean government (18SCIP-B066321-06, Development of Key Subsea Tunneling Technology).

Institutional Review Board Statement: Not applicable.

Informed Consent Statement: Not applicable.

Data Availability Statement: Not applicable.

Conflicts of Interest: The authors declare no conflict of interest.

\section{References}

1. Budach, C.; Thewes, M. Application ranges of EPB shields in coarse ground based on laboratory research. Tunn. Undergr. Space Technol. 2015, 50, 296-304. [CrossRef]

2. Peila, D.; Oggeri, C.; Borio, L. Using the slump test to assess the behavior of conditioned soil for EPB tunneling. Environ. Eng. Geosci. 2009, 15, 167-174. [CrossRef]

3. Budach, C. Untersuchungen zum Erweiterten Einsatz von Erddruckschilden in Grobkörnigem Lockergestein. Ph.D. Thesis, Bochum University, Bochum, Germany, 2012.

4. Pena Duarte, M.A. Foam as a Soil Conditioner in Tunnelling: Physical and mechanical properties of conditioned sands. Ph.D. Thesis, Oxford University, Oxford, UK, 2007. 
5. Quebaud, S.; Sibaï, M.; Henry, J.P. Use of chemical foam for improvements in drilling by earth-pressure balanced shields in granular soils. Tunn. Undergr. Space Technol. 1998, 13, 173-180. [CrossRef]

6. Wilms, J. Zum Einfluss der Eigenschaften des Stützmediums auf das Verschleißverhalten eines Erddruckschildes. Ph.D. Thesis, Gesamthochschule Essen University, Duisburg, Germany, 1995.

7. Tao, L.; Chen, Z.; Cui, J.; Wang, H.; Fang, Y. Experimental Methods to Assess the Effectiveness of Soil Conditioning with Foam in Fully Weathered Granite. Adv. Mater. Sci. Eng. 2019, 2019, 9046704. [CrossRef]

8. Lee, H.; Shin, D.; Kim, D.Y.; Choi, H. Study on EPB TBM performance by conducting lab-scaled excavation tests with different foam injection for artificial sand. J. Korean Tunn. Undergr. Space Assoc. 2019, 21, 545-560.

9. Zhou, X.; Yang, Y. Effect of Foam Parameters on Cohesionless Soil Permeability and Its Application to Prevent the Water Spewing. Appl. Sci. 2020, 10, 1787. [CrossRef]

10. Kim, T.H.; Kim, B.K.; Lee, K.H.; Lee, I.M. Soil conditioning of weathered granite soil used for EPB shield TBM: A laboratory scale study. KSCE J. Civ. Eng. 2019, 23, 1829-1838. [CrossRef]

11. Lee, K.I.; Yoon, Y.G.; Lee, J.W. Particle crushing properties of decomposed granite soil due to changes in the degree of weathering. J. Korean Geosynth. Soc. 2013, 12, 1-10. [CrossRef]

12. Ham, T.G.; Cho, Y.S.; Kim, Y.S. A study on the compression characteristics of decomposed granite soil based on single particle crushing property. J. Korean Geotech. Soc. 2004, 20, 103-111.

13. Kim, Y.J.; Lee, I.M.; Lee, I.K. Constitutive characteristics of decomposed Korean granites (1). J. Korean Geotech. Soc. 1994, 10, 55-78.

14. POSCO Engineering \& Construction Co., Ltd. Seoul Subway Line No. 9; Soil Report; POSCO Engineering \& Construction Co., Ltd.: Pohang, Korea, 2010.

15. Langmaack, L.; Lee, K.F. Difficult ground conditions? Use the right chemicals! Chances-limits-requirements. Tunn. Undergr. Space Technol. 2016, 57, 112. [CrossRef]

16. Langmaack, L.; Feng, Q. Soil conditioning for EPB machines: Balance of functional and ecological properties. In Proceedings of the International World Tunnel Congress and the 31st ITA General Assembly, Istanbul, Turkey, 7-12 May 2005. 